\title{
Model projections for household energy use in developing countries
}

\author{
Vassilis Daioglou $^{\mathrm{a}, *}$, Bas J. van Ruijven ${ }^{\mathrm{b}, \mathrm{d}, 2}$, Detlef P. van Vuuren ${ }^{\mathrm{b}, \mathrm{c}, 1}$ \\ ${ }^{a}$ Utrecht University, Copernicus Institute for Sustainable Development and Innovation, Department of Science, Technology and Society, Budapestlaan 6 , \\ 3584 CD Utrecht, The Netherlands \\ ${ }^{\mathrm{b}}$ Netherlands Environmental Assessment Agency (PBL), PO Box 1, 3720 BA Bilthoven, The Netherlands \\ ${ }^{c}$ Utrecht University, Utrecht Sustainability Institute, Willem C. van Unnikgebouw, Heidelberglaan 2, 3584 CS Utrecht, The Netherlands \\ ${ }^{\mathrm{d}}$ National Center for Atmospheric Research (NCAR), PO Box 3000, Boulder, CO 80307, United States
}

\section{A R T I C L E I N F O}

\section{Article history:}

Received 6 June 2011

Received in revised form

24 October 2011

Accepted 27 October 2011

Available online 17 December 2011

\section{Keywords:}

Household energy consumption

Energy modeling

Developing countries

Climate policy

\begin{abstract}
A B S T R A C T
The residential sector plays an important role in the energy system of developing countries. In this paper we introduce a bottom up simulation model for household energy use. The model describes energy demand for several end-use functions based on a set of physical drivers, such as floor space and heating degree days. The model also recognizes different population groups: i.e. urban and rural households, each distinguishing five income quintiles. The model is applied to analyze possible future developments of residential energy use in five developing world regions: India, China, South East Asia, South Africa and Brazil. We find that in each of these regions cooking is currently the main end-use function, but that other functions, such as space heating, cooling and appliances become more important. At the same time, energy consumption slowly shifts towards modern fuels. The model also shows that climate policy can reduce residential energy emissions, but could also slow down the energy transition away from traditional fuels in low income classes.
\end{abstract}

(c) 2011 Elsevier Ltd. All rights reserved.

\section{Introduction}

Residential energy use plays an important role in achieving a more sustainable development. First of all, residential energy use represents about $35 \%$ of global energy use and it therefore plays a key role in global energy-related environmental problems such as climate change and resource scarcity [1,2]. Urban air pollution and indoor air pollution are even more tightly related to residential energy use. Secondly, sufficient access to modern energy also forms a necessary condition for economic development and human well-being. In 2000, the international community made a commitment to the Millennium Development Goals (MDG's); a series of quantitative and time-bound targets aimed at tackling, among others, poverty, hunger, health, equality and environmental sustainability. Modi et al. (2005) and the IEA (2010) both show that access to modern energy forms a necessary condition for achieving these goals.

Model-based scenario analysis forms an important tool to explore the relationships between residential energy use, development and environmental issues. Most global energy models

\footnotetext{
* Corresponding author. Tel.: +31 30253 5392; fax: +31 302537601.

E-mail addresses: v.daioglou@uu.nl (V. Daioglou), vruijven@ucar.edu (B.J. van Ruijven), detlef.vanvuuren@pbl.nl (D.P. van Vuuren).

1 Tel.: +31302742046.

2 Tel.: +13034978387.
}

describe future residential energy demand based on relatively simple relationships between energy consumption and income or GDP per capita. This implies that trends are only understood in abstract variables such as energy intensity. Moreover, specific dynamics of developing countries, such as underdeveloped markets and informal activities, the transition from traditional to commercial fuels, electrification, the role of income distribution and the urban/rural difference are not modeled at all [3-5]. Subsequently current energy models tend to give poor results for developing countries [6].

A number of key energy functions (and associated drivers) play a role in residential energy use. Such functions include space heating and cooling, lighting, water heating, appliances and others [7-9]. Modeling these energy functions allows the study of the dynamics and possible future trends in this sector. Very few models currently follow such 'bottom-up' approach at the global scale, although some models exist for specific functions [10-13].

This study attempts to understand and subsequently project world-wide residential energy use using a bottom-up energy model which takes the heterogeneity of the residential sector in developing countries into account. The model (Residential Energy Model Global, REMG) described in this paper is based on an explicit representation of five energy functions in households and their main drivers for 26 world regions. Within each region, the model addresses heterogeneity by distinguishing between urban and rural 
population classes and furthermore disaggregates between income quintiles of the respective classes. In this paper the model is used to focus on detailed projections for residential energy use in India, China, ${ }^{3}$ South East Asia, ${ }^{4}$ South Africa and Brazil. These countries/ regions were selected due to their importance for global energy use as "newly industrialized economies", but also based on their climatic and social-economic differences. More specifically this paper deals with the following questions:

1. Given the data availability, is it possible to adequately model residential energy use on a global scale in a bottom up fashion?

2. What are the future trends of the residential energy use for India, China, South East Asia, South Africa and Brazil, and how do these trends differ?

3. What is the impact of specific policy interventions aimed at reducing greenhouse gas emissions in these five regions?

The REMG model is an expanded version of a model developed specifically for the Indian residential sector [14]. This model has been adapted for analysis of other regions and validated based on available historic data. The model validation is presented in the Appendix. It has been used to describe possible future trends based on the scenarios currently being developed by the Global Energy Assessment [15]. These scenarios are attractive in the context of this paper given their focus on environmental and development issues. Using the GEA scenarios, we look into possible developments under different assumptions for socio-economic development - but also on the impacts of climate policy by introducing a carbon tax.

In this paper, section 2 explains the methodology used by outlining the REMG model and a qualitative description of the scenarios is given. Section 3 summarizes the results of the baseline projections and the sensitivity analysis. Section 4 describes emissions pathways and the results of the climate policy scenario. Finally, section 5 offers a discussion on the methodology as well as some conclusions from the results.

\section{Methodology}

\subsection{Residential energy model - global}

REMG is a stylized bottom up household energy simulation model which describes the demand and supply of energy for different household energy functions $[14,16]$. There are a few key concepts that can be derived from the available literature on residential energy use. First of all, energy use in the residential sector can be best understood by focusing on specific end-use functions and their drivers [7,9]. By relating these functions to economic development it is thus possible to analyze changes in energy use. Secondly, in the literature, the concept of the energy ladder is often used to describe empirical trends of fuel switching from traditional fuels (e.g. wood and coal) towards modern fuels (natural gas and electricity) [17]. Finally, an important factor in residential energy use is the recognition of heterogeneity. Based on earlier research, income groups and urban/ rural classes have been identified as the most statistically significant in determining a households' energy consumption patterns [8].

Fig. 1 shows how in the model the primary drivers, secondary drivers and energy functions are related. In total, the model focuses on the five most important end-use functions [1]: i.e. cooking,

\footnotetext{
3 The China region consists of China, Hong Kong, Macau, Mongolia and Taiwan.

${ }^{4}$ South East Asia is made up of: Brunei Darussalam, Cambodia, East Timor, Indonesia, Laos, Malaysia, Myanmar, Papua New Guinea, Philippines, Singapore, Thailand and Vietnam.
}

appliances, space heating and cooling, water heating and lighting (these relationships are discussed in greater detail in section 2.1.1). The energy demand for the end-use functions is determined on the household level. The model uses five income quintiles for both the urban and rural population (population classes). After determining the energy demand per function (for each population class), supply by fuel type is determined on the basis of relative costs. The available energy carriers for each end-use function in the model are listed in Table 1 . Throughout this paper 'traditional biomass' and 'coal' are referred to as 'solid fuels' while the rest are considered 'modern fuels'. The REMG model in principle also describes more advanced fuels such as hydrogen and modern bio-energy but given our focus on scenarios up to 2030, we have decided not to include these fuels here. In this paper REMG is applied as a stand-alone model. However, it is normally applied within the energy system model TIMER [18] allowing to capture feedbacks between energy demand and energy prices.

It should be noted that the data requirement of the REMG model is considerable. Data is required for the drivers such as household expenditures, household sizes and income inequality. Data is also required for the energy consumption for the end-use functions in relation to these drivers. This includes ownership rates and unit energy consumption of household appliances and data on useful energy requirement for cooking and heating. Finally, information concerning fuel choice for each end-use function is needed. Unfortunately, such data are often not available from international data sources. We therefore had to consult many national data sources. While important data gaps remain, especially in time series, we were able to find enough data to determine relationships and calibrate the model.

Household information and appliance ownership was primarily collected from censuses and surveys of each country but also from the World Development Indicators of the World Bank [19-25]. For income inequality, databases of the World Bank were used [26,27]. Total final consumption of energy for the residential sector on a global scale is available from the International Energy Agency, which also breaks down the energy use to different fuels [2]. More detailed data concerning the urban/rural divide, energy use per energy function, fuel shares, fuel subsidies etc, were gathered from scientific papers and independent databases [28-33]. Data concerning the difference in cooking fuels between urban and rural households is available from the World Health Organization [34]. The model was calibrated against the available data in order to ensure that key indicators match historic observations. The calibration consists of data regression and manual parameter estimation and is aimed to ensure that household properties, appliance ownership, cooking fuel choice and final energy use reflected the data mentioned above as much as possible.

\subsubsection{End use functions}

The demand of the five end-use functions are determined in terms of Useful Energy (UE), that is, energy delivered to the end-use functions adjusted for conversion efficiency between energy carriers. The choice of functions and their relationship with the primary drivers is based on the methodology adopted by van Ruijven et al. [14]. In all the following equations the subscript ' $R$ ' denotes regional variation, ' $p$ ' denotes urban/rural class difference, ' $q$ ' denotes income quintile, and ' $a$ ' different appliances. Below, we briefly discuss the relationships derived for each end-use function. A detailed account of the data analysis can be found elsewhere [16].

2.1.1.1. Cooking. In developing regions, cooking often represents the most significant end-use function. In developed countries, however, other end-use functions take precedence [9,35]. We analyzed historical data for cooking energy use from different parts of the 


\begin{tabular}{|c|c|c|c|c|c|}
\hline $\begin{array}{l}\text { Primary Drivers } \\
\text { Population } \\
\text { (P) }\end{array}$ & \multicolumn{2}{|c|}{$\begin{array}{l}\text { Household } \\
\text { Expenditure } \\
\text { (Y) }\end{array}$} & $\begin{array}{l}\text { Population } \\
\text { Density } \\
\text { (PD) }\end{array}$ & $\begin{array}{l}\text { Household } \\
\text { Size } \\
\text { (S) }\end{array}$ & $\begin{array}{l}\text { Temperature } \\
\text { (T) }\end{array}$ \\
\hline & & & \multicolumn{2}{|c|}{$\begin{array}{l}\text { Intermediate Drivers } \\
\text { Floorspace } \\
\text { F = } f(Y, P D)\end{array}$} & $\begin{array}{l}\text { trification } \\
=f(Y)\end{array}$ \\
\hline \multicolumn{6}{|c|}{ Energy Functions (Demand) } \\
\hline $\begin{array}{l}\text { Cooking } \\
f(P, Y)\end{array}$ & $\begin{array}{l}\text { Appliances } \\
f(P, Y, S, E)\end{array}$ & \multicolumn{2}{|c|}{$\begin{array}{l}\text { Space Heating/Cooling } \\
f(P, Y, T, F)\end{array}$} & $\begin{array}{l}\text { Water Heating } \\
\qquad(P, Y, T)\end{array}$ & $\begin{array}{c}\text { Lighting } \\
f(P, Y, S, F, E)\end{array}$ \\
\hline
\end{tabular}

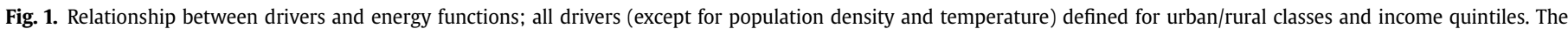
relationships between these parameters are described in section 2.1.1.

world. The total range (69 data points) was $0.77-7.22 \mathrm{MJUE} / \mathrm{cap} /$ day The vast majority of data points (44) clustered around 1.5 and 3.5 $\mathrm{MJUE}_{\mathrm{UE}}$ cap/day. No statistically significant relationship was found between energy for cooking and income or geographical region. Therefore it was assumed that all regions have an average constant consumption of $3 \mathrm{MJUE}_{\mathrm{UE}} / \mathrm{cap} / \mathrm{day}$.

2.1.1.2. Appliances. Appliances represent an important end-use function which can be directly related to household expenditures. Three different categories of appliances are modeled. These include 1) food storage and processing, 2) washing/cleaning and 3) entertainment. Within these categories eight indicative appliances are modeled. The appliance penetration is based on a gompertz function, equation (1). The gompertz function has been selected since its asymmetric logistic growth can model the uptake of appliances of poor households with a rapid initial growth followed by a gradual approach towards saturation.

$$
\begin{aligned}
\text { Penetration }_{R, p, q} & =\text { Saturation }_{R} \times \operatorname{EXP}\left(-\varphi 1_{R, p}\right. \\
& \left.\times \operatorname{EXP}\left(-\left(\frac{\varphi 2_{R, p}}{1000}\right) \times \operatorname{HHExp_{R,p,q}}\right)\right)
\end{aligned}
$$

Here, HHExp is the household expenditures disaggregated for regions, urban/rural class and income quintiles. The saturation level is the maximum number of appliances per household, which may vary with time. The gompertz parameters $(\varphi 1$ and $\varphi 2)$ are region and class specific determined via regressions on available data points (global if local data was not available) [16].

Table 1

Energy carriers available for each end-use functions.

\begin{tabular}{lllll}
\hline Cooking & $\begin{array}{l}\text { Appliances/ } \\
\text { Space cooling }\end{array}$ & $\begin{array}{l}\text { Space } \\
\text { heating }\end{array}$ & $\begin{array}{l}\text { Water } \\
\text { heating }\end{array}$ & Lighting \\
\hline Coal & Electricity & $\begin{array}{l}\text { Coal } \\
\text { Traditional } \\
\text { braditional } \\
\text { biomass }\end{array}$ & $\begin{array}{l}\text { Coal } \\
\text { Traditional } \\
\text { biomass }\end{array}$ & Kerosene \\
$\begin{array}{c}\text { Kerosene } \\
\text { Liquid } \\
\text { petroleum Gas }\end{array}$ & & $\begin{array}{l}\text { Liquid } \\
\text { Natural gas }\end{array}$ & $\begin{array}{l}\text { Liquid } \\
\text { Natural gas }\end{array}$ & Electricity \\
$\begin{array}{l}\text { Natural gas } \\
\text { Modern } \\
\text { bio-energy }\end{array}$ & Hydrogen & Hydrogen & \\
Electricity & & Modern & Modern & \\
& & bio-energy & bio-energy & \\
& & Secondary & Secondary & \\
heat & heat & \\
& & Electricity & Electricity & \\
\hline
\end{tabular}

In order to determine energy use, the ownership levels are multiplied by the unit energy consumption. It is assumed that efficiency changes over time based on autonomous as well as price induced energy efficiency improvements. The autonomous energy efficiency improvement describe in equation (2) is assumed to be a simple decay over time as verified from data [1,36-39].

$U E C=\alpha_{R, a} \times \beta_{R, a}^{(t-1971)}+U E C m_{R, a}$

Here $\alpha$ and $\beta$ determine the rate of autonomous decline and $U E C m$ is an assumed lower limit to UEC (based on extrapolation of trends and available information on minimum energy consumption by end-use type) [16].

For the price induced energy efficiency improvement, the UEC is related to the cost of electricity (coe) as shown in equation (3). The parameter coe not only includes the electricity price, but also the annualized capital cost for use of electricity based on the current prices and efficiency ratings of certain appliances [40-42]. The assumption is that appliance choice for each household is based on annualized total costs, weighing the advantage of reduced energy costs against the additional investments into efficiency. This priceinduced efficiency improvement is assumed to occur on top of the autonomous improvement mentioned above. The coefficients $\alpha$ and $\beta$ for equation (3) are determined based on the most attractive option for any given consumer discount rate [16]. Thus for low-income households with high consumer discount rates where capital costs are important, the effect of a higher cost of electricity is lower. The consumer discount rate is discussed in greater detail in section 2.1.2.

$U E C_{R, p, q, a}=\alpha_{R, p, q, a} \times \operatorname{Ln}\left(\operatorname{coe}_{R}\right)+\beta_{R, p, q, a}$

2.1.1.3. Space heating and cooling. In richer households, space heating and cooling represents the greatest share of energy demand. Space heating demand is modeled as a function of floorspace $\left(\mathrm{m}^{2} / \mathrm{cap}\right)$, population size (capita), heating degree days (HDD) and heating intensity $\left(\mathrm{kJuE} / \mathrm{m}^{2} / \mathrm{HDD}\right)$ directly after Isaac and van Vuuren [13].

HeatUE $_{R, p, q}=$ Population $_{R, p, q} \times$ FloorSpace $_{R, p, q} \times$ UEInt $_{R} \times H_{R}$

In equation (4), UEInt is the useful energy heating intensity $\left(\mathrm{kJUE} / \mathrm{m}^{2} /{ }^{\circ} \mathrm{C} / \mathrm{yr}\right)$ which is also sensitive to energy costs, with heating intensity reducing as costs go up based on available technologies. 
Floorspace is in $\mathrm{m}^{2}$ /cap and it is assumed to be a function of income levels and population density. The heating degree days are determined on the basis of a relationship with monthly mean temperature.

Energy use of air conditioners is based on their penetration, unit UEC (energy consumption) and efficiency improvement (5):

ACEnergy $_{R, p, q}=$ Penetration $_{R, p, q} \times \frac{U E C_{R, p, q}}{\text { Efficiency Change }^{-}}$

The UEC is adjusted for efficiency changes to the average EER (Energy Efficiency Ratio) projections [43]. The penetration depends on an expenditure based gompertz growth towards a climate based maximum saturation value. The relationship between maximum saturation and CDD (cooling degree days) is exponential and has a maximum of $100 \%$ [11,44]. The UEC has a linear relationship with the cooling degree days (CDD) and a logarithmic relationship with income in order to account for multiple ownership of air cooling appliances (6):

$U E C_{R, p, q}=C D D_{R} \times\left(0.6053 \times \ln \left(\operatorname{HHExp}_{R, p, q}\right)-3.1897\right)$

Again, CDD is based on a relationship with monthly mean temperature.

2.1.1.4. Water heating. The growth in demand for warm tap water is modeled as a function of income towards a maximum value that is determined by heating degree days (cold regions tend to use warmer tap water). The data used to construct this relationship comes from a number of sources covering many climatic regions $[1,45-51]$.

$$
\begin{aligned}
\text { WaterUE }_{R, p, q}= & \operatorname{MaxUE}_{R} \times(1-\operatorname{EXP}(3.356 \\
& \left.\left.\times \operatorname{EXP}\left(-\left(\frac{0.237}{1000}\right) \times \operatorname{HHExp}_{R, p, q}\right)\right)\right)
\end{aligned}
$$

Where MaxUE in equation (7) is the maximum useful energy requirement for water heating based on a linear increase with HDD.

2.1.1.5. Lighting. In low income countries lighting can account for a significant share of total electricity use while in OECD countries it represents only a small fraction of total energy use [39,52]. In households which lack access to electricity, lighting demand is met by a given quantity of kerosene [53]. For electrified households, data suggests that lighting demand (at frozen efficiency) forms a linear relationship with floor space. Hence, we used the floorspace trends to estimate the number of lighting fixtures per household. This is multiplied by the average wattage of lights (assumed uniform), and provides the total lighting capacity of the household. Finally this can be multiplied by a Lighting-Hours factor (the equivalent time that all lights are on). The formula has been fit to the available data [16].

$$
\begin{aligned}
\text { LightingEnergy }_{R, p, q}= & 0.68 \times \text { Floorspace }_{R, p, q} \times \text { Wattage } \\
& \times \text { LightingHoursFactor }^{\text {Ling }}
\end{aligned}
$$

The wattage is determined by a choice between standard (incandescent) bulbs and efficient (compact fluorescent) lighting, based on the annual fuel and annualized capital costs. Market shares of the respective technologies are allocated based on the multinomial logit function (explained below). The costs of incandescent lamps are set as constant while there is a decrease over time in the price for compact fluorescent bulbs towards a minimum [39,54].

\subsubsection{Fuel choice}

The next step is to determine what fuels are used in order to meet the demand of the different energy functions. The energy carriers which are incorporated in this study are coal, traditional biomass, liquid fuels (kerosene and LPG), natural gas, secondary heat and electricity. The availability of these fuels per end-use function is indicated in Table 1. For appliances (including space cooling equipment) only electricity is used. For lighting either electricity or kerosene is used based on the assumed access to electricity.

For each function, the actual allocation of fuel shares (FS) of each energy carrier $(E C)$ is determined by a multinomial logit function based on the total perceived cost $(C)$ :

$F S_{R, p, q, E C}=\frac{e^{-\lambda C_{R, p, q, E C}}}{\sum_{E C=1}^{E C_{\text {tot }} e^{-\lambda C_{R, p, q, E C}}}}$

Equation (9) is used together with certain other equations explained below in order to simulate the energy ladder for the space/water heating and cooking end-use functions. The energy ladder is the empirical observation that as households get richer, they switch towards cleaner, more efficient and convenient fuels; thus away from coal and traditional biomass (solid fuels) and towards kerosene, LPG, natural gas and electricity [5,17]. The energy ladder concept has been criticised as an oversimplification since households tend to use multiple fuels rather than completely switch from one to another, while it also does not explain underlying drivers [55].

In the REMG model, the energy ladder is simulated as part of equation (9) by introducing two factors: 1) income dependant consumer discount rates simulate the effect that front end capital investments are more feasible for richer households than for poor, and 2) an income dependent disadvantage-factor represents the importance of perceived (non-monetized) downsides of cheap-butdirty fuels (e.g. time for collecting, indoor smoke). Thus, based on behavioural rules, this leads indirectly to behavior similar to the energy ladder while also accounting for multiple fuel use, as the market shares are determined by fraction and heterogeneity (income class and urban/rural population). As a result, always several fuels are used at the same time.

The consumer discount rates are important in determining the annualized capital costs. Empirical evidence shows that the applied discount rates for fuel choices are much higher for low income households (up to 80\%) that for affluent households (down to $10 \%$ ) $[56,57]$. These phenomena stem from the lower liquidity of the poor and the difficulty to obtain (low interest) loans. In the REMG model, discount rates are assumed to decrease with income and, hence, annualized costs also decrease with income.

The perceived costs represent the fact that fuel choice is not only the product of economic factors alone. Factors that play a significant role are habits and cultural factors, infrastructure, environmental factors and convenience. Habits, for instance, include specific traditional cooking methods as well as cooking for large groups where traditional biomass is more effective than modern fuels $[55,58,59]$. In the model, the perceived costs are determined for the historical period based on the calibration of the fuel market shares. It is assumed that the perceived costs change with income. The assumption is that along with income also factors like employment/education and the value of time, change - leading to more rational behavior. The rate at which these costs fall is based on available income level data on fuel use: it is assumed that less convenient fuels decrease in attractiveness, while electricity and natural gas increase. Next to the income dependent perceived costs, a final factor is applied to calibrate market shares to historic observation. This factor represents remaining market distortions 
that still play a role, even in richer countries, such as consumer preferences and infrastructural barriers. In the long run, the fuel choice of cooking for rich households boils down to the choice between natural gas and electricity. Since no preference can be determined beforehand, we linked the attractiveness of natural gas inversely to the fraction of it which is imported, determined from projections of the energy system TIMER model [60,61].

The total annual costs of each energy option (or the perceived costs (C) in eqn. (9)) are the sum of annualized capital costs (CC), fuel costs (price) and fuel-specific penalties $(P)$ :

$$
\begin{aligned}
C_{p, q, E C(t)}= & \frac{C D R_{p, q(t)}}{1-\left(1+C D R_{p, q(t)}\right)^{L T_{E C}}} \cdot C C_{E C}+\frac{U E_{p, q(t)}}{E f f_{E C}} \cdot \text { price }_{p, q, E C(t)} \\
& +P_{p, q, E C(t)}
\end{aligned}
$$

Where CDR is the consumer discount rate. Taken together, the description of the discount rate, the perceived costs and the multinomial logit model are able to represent the dynamics behind the energy ladder endogenously within the model. In contrast to a purely empirical description, however, this method also allows to describe the impact of other variables, such as fuel prices. For instance, movement down the fuel ladder may be possible under price hikes. The use of electricity for a cooking/heating fuel depends also on electrification rates which are available from an electrification model [62].

In REMG, equation (9) is used to determine market shares of investments in new (marginal) end-use capital stock. Next, a vintage stock depends on the lifetime of appliances, stoves and boilers. Effectively, this builds time-lag in fuel switching (as only new capital responds to changes in circumstances) and prevents energy transitions happening overnight. These delays in stock turnover apply to appliances as well, with relevant consequences for efficiency improvement.

Finally, each fuel (or stove type) has its own final conversion efficiency, with which the demand for useful energy is met. For instance, fuel wood has a typical conversion efficiency of $15 \%$, whereas LPG stoves convert about $60 \%$ of the fuel's energy to cooking energy. A literature review of cooking and heating efficiencies of the different fuels was conducted yielding a range of efficiencies [33,50,63-68]. For any given fuel, the current efficiency level is based on average values. Future (aggregate) values are based on the best available technologies today.

\subsection{Scenario assumptions}

\subsubsection{Baseline scenario}

We used the model to explore possible trends in residential energy use in major developing countries based on the scenarios of the Global Energy Assessment [15]. The three GEA scenarios are all targeted at achieving as set of scenario development goals (improving energy access, reducing air pollution, avoiding dangerous climate change and improving energy security) but on the basis of three different pathways with respect to energy demand: 1) high demand (low efficiency), 2) low demand (high efficiency) and 3) a medium development. The GEA scenarios have been implemented in the IMAGE/TIMER model. Here we use the third scenario as the baseline. In this scenario, a business as usual assumption is used for efficiency improvement for both appliances and cooking technology (Table 2). The heating efficiencies are based on existing projections using the IMAGE/TIMER model [13]. Space cooling efficiency increase is based on increases in EER after Rong et al. [43]. The distribution of wealth between urban and rural populations as well as urbanization rates are derived from projections by IIASA [69]. Concerning the distribution of expenditures
Table 2

Value cooking efficiency improvement under baseline.

\begin{tabular}{lll}
\hline & Cooking efficiency & \\
\cline { 2 - 3 } & 2007 & 2030 \\
\hline Coal & 0.15 & 0.23 \\
Traditional biomass & 0.14 & 0.21 \\
Kerosene & 0.503 & 0.51 \\
LPG & 0.604 & 0.625 \\
Natural gas & 0.604 & 0.66 \\
Electricity & 0.713 & 0.75 \\
\hline
\end{tabular}

Table 3

GINI coefficients for each region and urban/rural category.

\begin{tabular}{lll}
\hline Region & Urban & Rural \\
\hline India & 37.6 & 30.5 \\
China & 34.5 & 35.7 \\
South East Asia & 38.7 & 32.8 \\
South Africa & 53.2 & 50.5 \\
Brazil & 56.7 & 52.8 \\
\hline
\end{tabular}

Table 4

Future assumption on regional population and household expenditure change.

\begin{tabular}{llcllr}
\hline & $\begin{array}{l}\text { Population } \\
\text { (million) }\end{array}$ & & & \multicolumn{2}{l}{$\begin{array}{l}\text { Household } \\
\text { expenditures } \\
(\$ 2005 / \text { cap })\end{array}$} \\
\cline { 2 - 3 } \cline { 5 - 6 } & 2007 & & & 2007 & 2030 \\
\hline India & 1160 & 1490 & & 1337 & 3903 \\
China & 1360 & 1500 & & 2206 & 5977 \\
South East Asia & 575 & 717 & & 2658 & 6752 \\
South Africa & 49.2 & 54.9 & & 6017 & 11466 \\
Brazil & 190 & 217 & 5756 & 9971 \\
\hline
\end{tabular}

amongst quintiles, the inequality in 2007 for each region is assumed to remain the same as current values as implied by GEA projections on inequality (Table 3 ). The total regional population and household expenditures are shown in Table 4.

\subsubsection{Climate policy}

As an experiment, we look into the impact of climate policy on residential sector greenhouse gas emissions and development goals. Climate policy is represented by a constant carbon tax of 100 $\$ 2005 / \mathrm{tCO}_{2}$ introduced on commercial fuels for the period 20102030. The underlying hypothesis of such a tax is that by internalizing externalities, high-emissions fuels become less attractive. However, the effect is less straightforward for poor households as traditional fuels are likely to be unaffected by the carbon price. Application of a model with sufficient detail in terms of income classes and fuel types, such as REMG, can explore the impact of climate policies in such situation better than aggregated models. Since the experiment is performed to see the effect of climate policy on development and climate aspects of residential energy use, we ask the following questions: 1) Does a carbon tax promote fuel switching to cleaner fuels? 2) Do the overall emissions fall as planned? 3) How does it affect the population reliant on solid fuels for cooking?

Once the $100 \$_{2005} / \mathrm{tCO}_{2}$ tax is implemented, the ensuing fuel prices and the emission factor of electricity are determined from TIMER runs. Since the motivation for a carbon tax is that cleaner fuels become more attractive and users turn away from dirty fuels, the emission factor of electricity (determined in the power and not the residential sector) decreases significantly with higher taxes 
Table 5

Change in regional electricity emission factor (kgCeq/GJe) under baseline and $100 \$ 2005 /$ tCO2 tax scheme based on TIMER calculations.

\begin{tabular}{lcll}
\hline & \multicolumn{2}{l}{$\begin{array}{l}\text { Electricity Emission } \\
\text { factor }(\mathrm{kgC} / \mathrm{GJ})\end{array}$} \\
\cline { 2 - 4 } & 2007 & $\begin{array}{l}2030 \\
\text { baseline }\end{array}$ & $\begin{array}{l}2030100 \$_{2005} / \mathrm{tCO}_{2} \\
\operatorname{tax}\end{array}$ \\
\hline India & 65.08 & 52.31 & 19.50 \\
China & 68.10 & 53.37 & 29.77 \\
South East Asia & 42.06 & 41.24 & 16.63 \\
South Africa & 60.50 & 56.30 & 31.94 \\
Brazil & 9.27 & 10.10 & 0.86 \\
\hline
\end{tabular}

(Table 5). The experiment is conducted with both baseline and carbon tax electricity emission factors in order to compare the reduction potential of residential energy use under a carbon tax due to the residential sector and the power sector separately.

\section{Baseline projections}

The following paragraphs describe the model results (final energy use) for different regions as well as a sensitivity analysis. We first discuss total residential energy use, and next focus on the different end-use functions as well as the use of electricity. Where appropriate, the difference between urban/rural localities and income quintiles are also highlighted. Since this paper focuses on development the results presented focus around energy functions, fuel use and access to clean cooking fuels.

\subsection{Total residential energy use}

In all regions, the assumed income increase in the baseline scenarios leads to an increase in energy demand for different energy functions and a diversification of the fuel supply. Fig. 2 shows the projected final energy use by end-use function in 2007 and in 2030 under the baselines for each of the studied regions for urban and rural households.

As shown in Fig. 2 (by comparing 2007 and 2030 columns), the first end-use functions that are met are cooking and lighting. While lighting energy demand only forms a small share of total demand, in most regions cooking forms the most dominant enduse function. As households get richer, energy use for appliances, space heating/cooling and water heating gain importance. In China and South Africa space and water heating are projected to become important for energy given the climatic conditions. In contrast, in India, South East Asia and Brazil space cooling is more important.

For urban energy use, appliances and cooling become important end-use functions, while for rural energy use cooking continues to dominate the picture for a much longer period of time. The exception here is formed in China and South Africa where space heating also is important for rural households (again, as a result of climatic conditions). Appliance energy use and space cooling are lower in rural regions due to lower income levels, but also lower electrification rates.

Fig. 3 shows the total final energy use per capita by energy carrier. As can be seen, traditional fuels hold a large share in the final energy use of all regions looked at in this paper, especially in 2007 and in rural areas. With increasing income levels, the model shows that households switch towards cleaner (and more efficient) fuels. In several, cases this even reduces the total per capita energy consumption: This is the case for rural households in all regions except China where the large increase in space heating energy demand results in a net increase of the overall demand. Furthermore, China and South Africa are the only regions which show a significant use of coal (especially for rural households) as it represents a cheap and abundant supply in these regions.
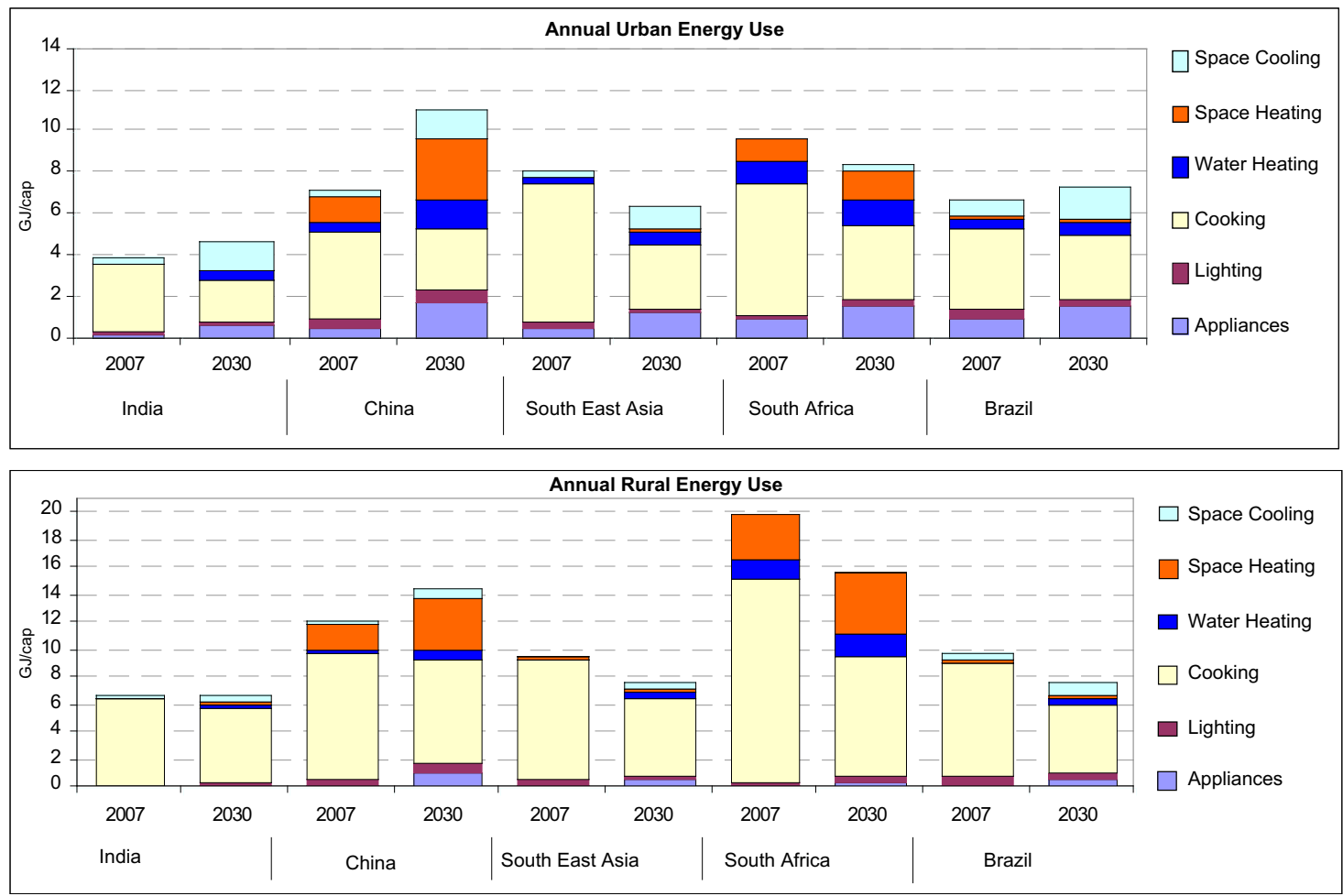

Fig. 2. Annual final energy use per capita $\left(\mathrm{GJ}_{\mathrm{SE}} / \mathrm{cap}\right)$ by end-use function, urban (upper) and rural (lower) areas. 

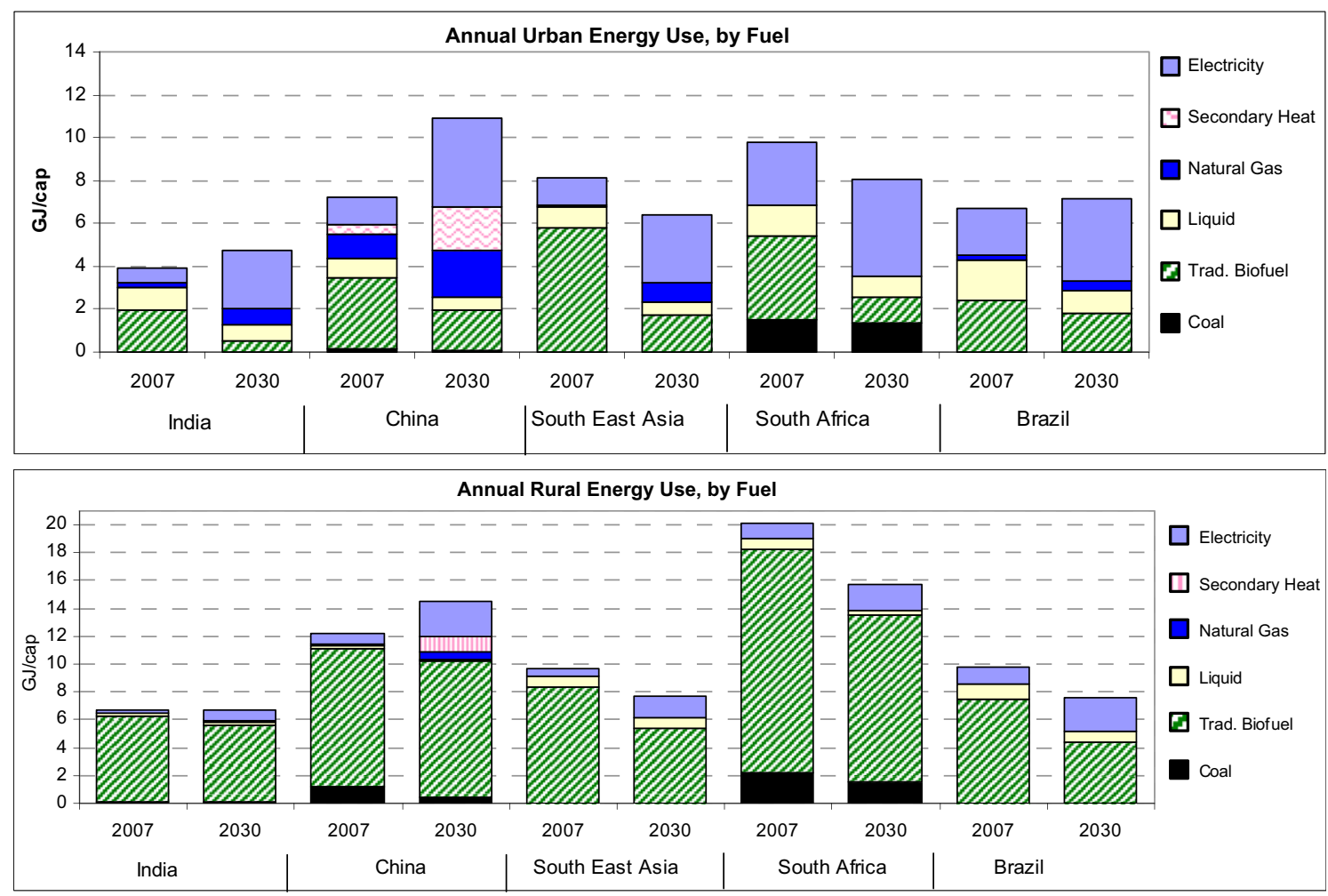

Fig. 3. Annual final energy use per capita ( $\mathrm{GJ}_{\mathrm{SE}} / \mathrm{cap}$ ) by fuel, urban (upper) and rural (lower) areas.

The projected 2030 per capita energy consumption levels in Fig. 3 range from 4 to $20 \mathrm{GJ}$ SE/cap,. Households in the USA, however, currently consume about $45 \mathrm{GJ} \mathrm{SE} /$ (about half of this is for space and water heating) indicating that even in 2030 there is a huge potential for further increase in energy use. The countries we analyze do not reach such high levels of energy demand even amongst the richest cohort, partly as a result of climatic differences, but also due to lower household expenditures. Energy use of OECD regions are not predicted to change much in the studied time frame $[70,71]$.

\subsection{Cooking and heating}

The projected use of energy for cooking is detailed further in Fig. 4. The supply of cooking energy use is dominated by traditional fuels, especially in rural areas. The demand for cooking energy falls for both urban and rural households due to fuel switching, which leads to the use of more efficient fuels, as well as autonomous increases in efficiency for any given fuel.

Fig. 5 shows the cooking capital for urban and rural households per quintile for India. This nicely illustrates the transition from traditional to modern fuel across the different income quintiles. For the lowest rural quintiles (R1 and R2), almost no changes are projected between 2007 and 2030: at the same time, very significant changes occur for the cohorts R3, R4, R5, U1 and U2. This implies that inequality and poverty also play a key role in the fulfilment of energy functions. Poverty can act as a significant barrier to fuel switching leading to a situation in which the poorest households only meet the basic functions using solid fuels. Furthermore, it can be seen that also LPG and kerosene are in the long-run replaced by natural gas and to a lesser extent, electricity.

The demand for heating is driven by climate factors and household expenditures. Fig. 6 shows the space and water heating energy use per capita by fuel. As can be seen, increases in heating demand in rural India, South East Asia and South Africa are primarily met by increased use of traditional biomass. This is not true in the more prosperous urban households. In urban China, the model assumes that secondary heat becomes the dominant heating fuel (the underlying energy system calculation shows that natural gas is only available through major imports making it a less favored choice). South Africa is the only region which currently uses significant amounts of electricity to meet both cooking and heating functions. It is projected that this situation does not change. The projections show, finally, that gaseous and liquid fuels dominate urban India, South East Asia and Brazil.

\subsection{Electricity use}

Fig. 7 shows the residential use of electricity by end-use functions. The projection expects electricity use to increase in all regions for both urban and rural populations. The increase is mainly attributed to appliances and cooling but also cooking in (due to fuel switching) and heating in South Africa as heating demand grows (as already mentioned, South Africa already has a high use of electricity for heating). In rural households, electricity use is projected to remain significantly lower that urban areas due to lower expenditures and lower electrification rates.

\subsection{Sensitivity analysis}

We have tested the sensitivity of the model to several key uncertainties: household expenditures and the price of oil. For the former, we increased the values of the default scenario gradually over $2008-2015$ to $115 \%$ of the absolute values, see Table 4 . For the latter we assume a $50 \%$ price increase. The development of the global price of oil (excluding regional taxes) in the baseline assumes 

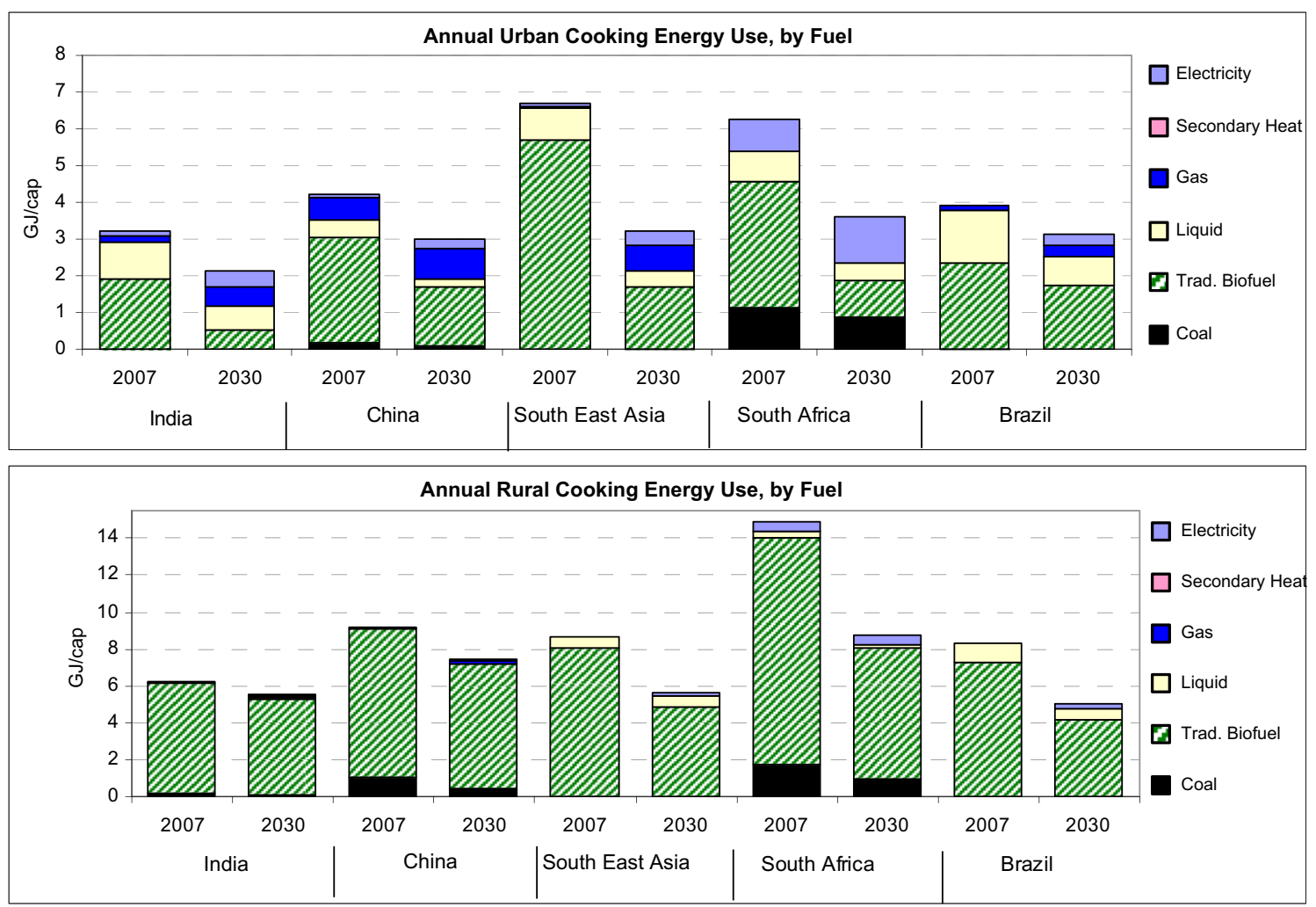

Fig. 4. Annual final energy use per capita (GJ $J_{S E} /$ cap) for cooking by fuel, urban (upper) rural (lower) areas.

an increase from $10.5 \$ 2005 / G J$ in 2007 to $13.5 \$ 2005 / G J$ in 2030 . The baseline and sensitivity analysis projections are shown in Fig. 8

A change in projections of household expenditure leads to increased energy demand as well as further diversification of fuel use. The $15 \%$ increase implied in the sensitivity analysis further decreases the share of cooking in final energy use but not significantly. This decrease is due to two reasons: 1) increased satisfaction of other needs and 2) fuel switching towards cleaner fuels.
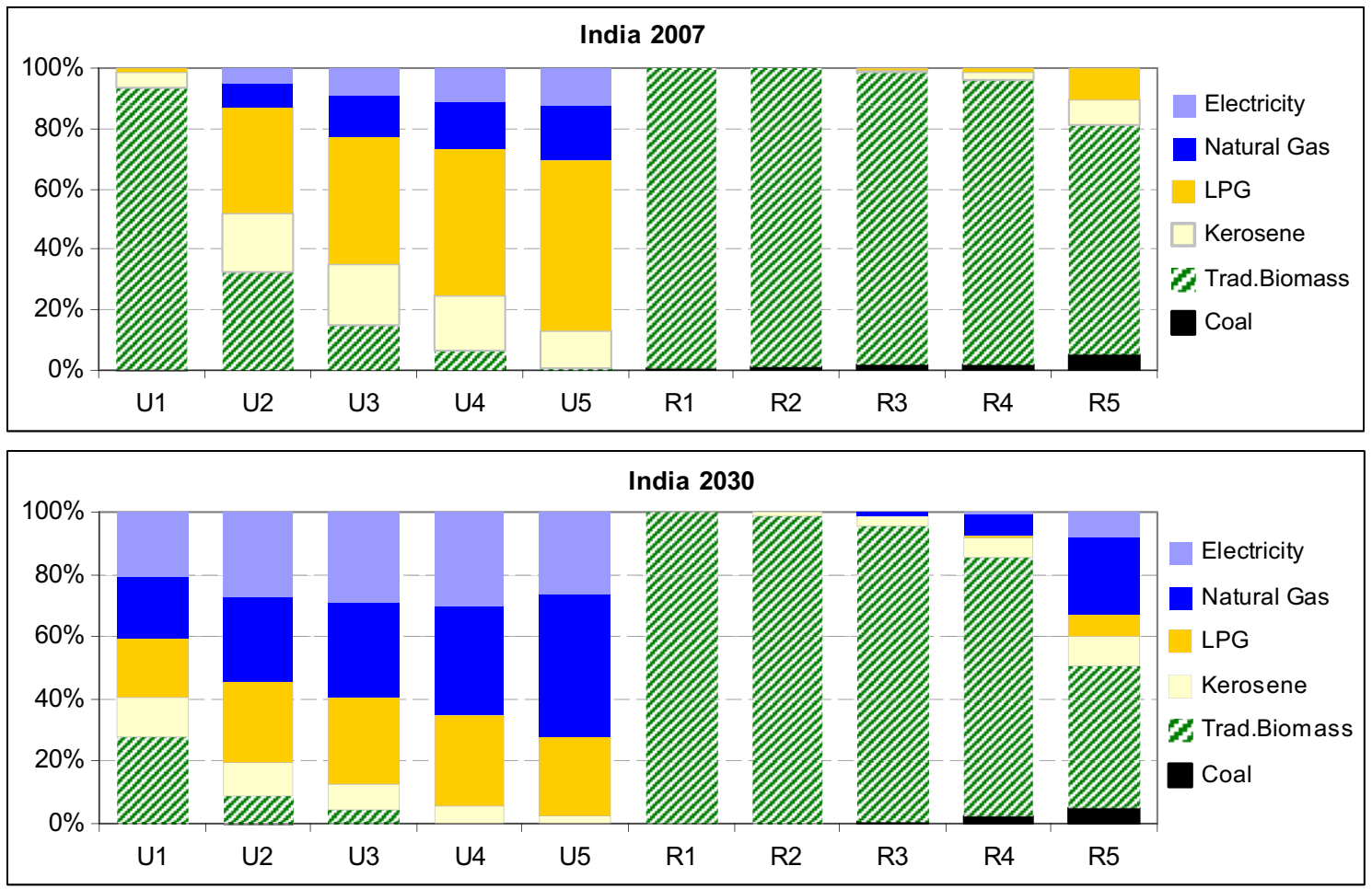

Fig. 5. Shares of cooking capital in India in 2007 (upper) and in 2030 (lower), urban/rural quintiles. 

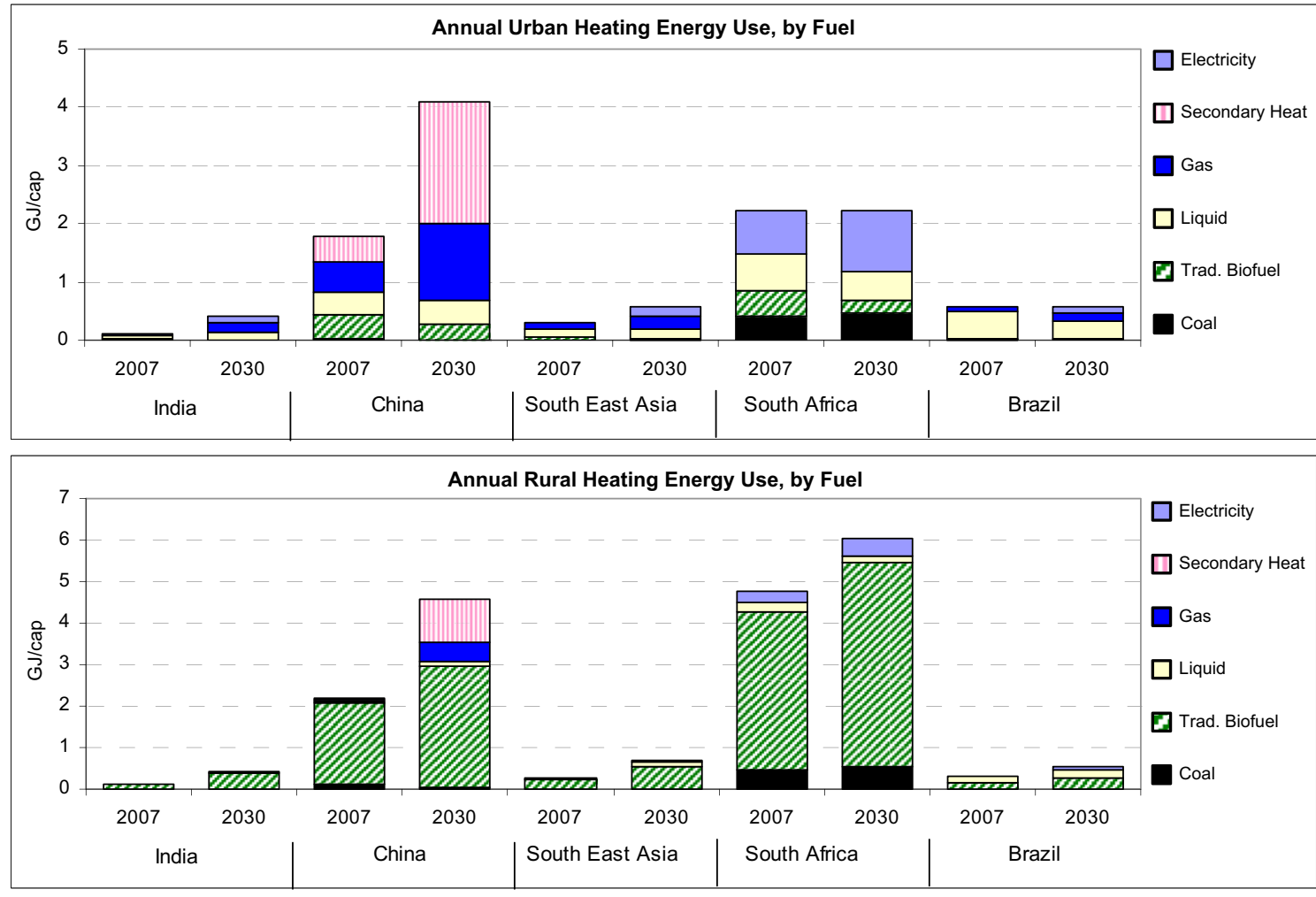

Fig. 6. Annual final energy use per capita (GJSE/cap) for space and water heating by fuel, urban (upper) and rural (lower) areas.
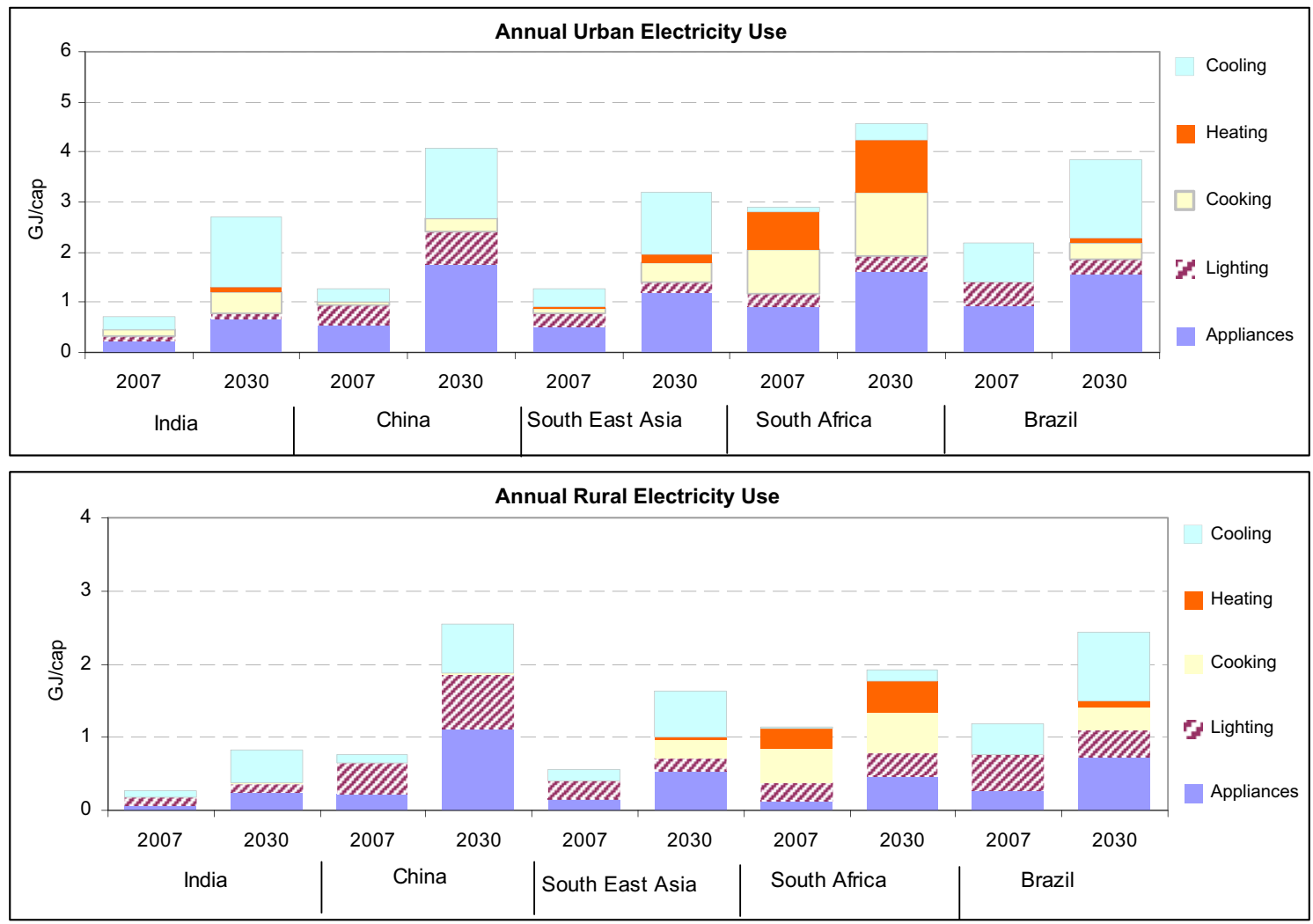

Fig. 7. Annual electricity use per capita (GJ/cap) by function, urban (upper) and rural (lower) areas. 


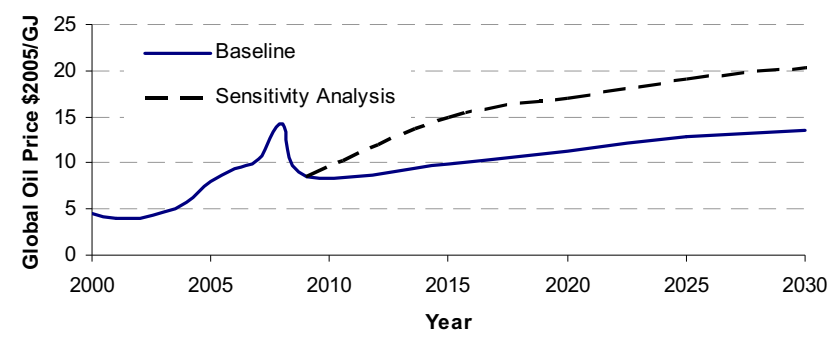

Fig. 8. Baseline and sensitivity analysis projections for global oil price $\left(\$_{2005} / G J\right)$.
Table 6 shows the final energy use in 2007, under the baseline projections and together with the $15 \%$ increase on household expenditures. Also shown in brackets is how much of this energy is provided by electricity. Both the final energy use and the electricity use are sensitive to household expenditures. For both urban and rural households there is an obvious increase in final energy use due to increased use of other functions such as appliances, air conditioning and space/water heating. For rural households the relative increase in use of electricity is greater (7-19\%) than urban households (7-14\%) due to limited switching under the baseline.

Table 6

Total final energy use (GJSE/cap) and electricity use (in brackets) under baseline and household expenditure sensitivity test for urban and rural households.

\begin{tabular}{|c|c|c|c|c|c|c|}
\hline & \multicolumn{3}{|l|}{ Urban } & \multicolumn{3}{|l|}{ Rural } \\
\hline & 2007 & Baseline & $\begin{array}{l}\text { Household } \\
\text { expenditures }+15 \%\end{array}$ & 2007 & Baseline & $\begin{array}{l}\text { Household } \\
\text { expenditures }+15 \%\end{array}$ \\
\hline India & $3.92(0.72)$ & $4.71(2.69)$ & $5.03(3.07)$ & $6.74(0.28)$ & $6.74(0.82)$ & $6.79(0.98)$ \\
\hline China & $7.21(1.28)$ & $10.88(4.08)$ & $11.31(4.37)$ & $12.18(0.77)$ & $14.53(2.54)$ & $14.88(2.70)$ \\
\hline South East Asia & $8.15(1.28)$ & $6.41(3.18)$ & $6.57(3.58)$ & $9.70(0.55)$ & 7.75 (1.63) & $7.64(1.81)$ \\
\hline South Africa & $9.76(2.89)$ & $8.08(4.58)$ & $8.36(5.01)$ & $20.11(1.15)$ & $15.74(1.91)$ & $16.19(2.14)$ \\
\hline Brazil & $6.70(2.19)$ & $7.16(3.84)$ & $7.35(4.32)$ & $9.79(1.17)$ & $7.64(2.44)$ & $7.65(2.73)$ \\
\hline
\end{tabular}
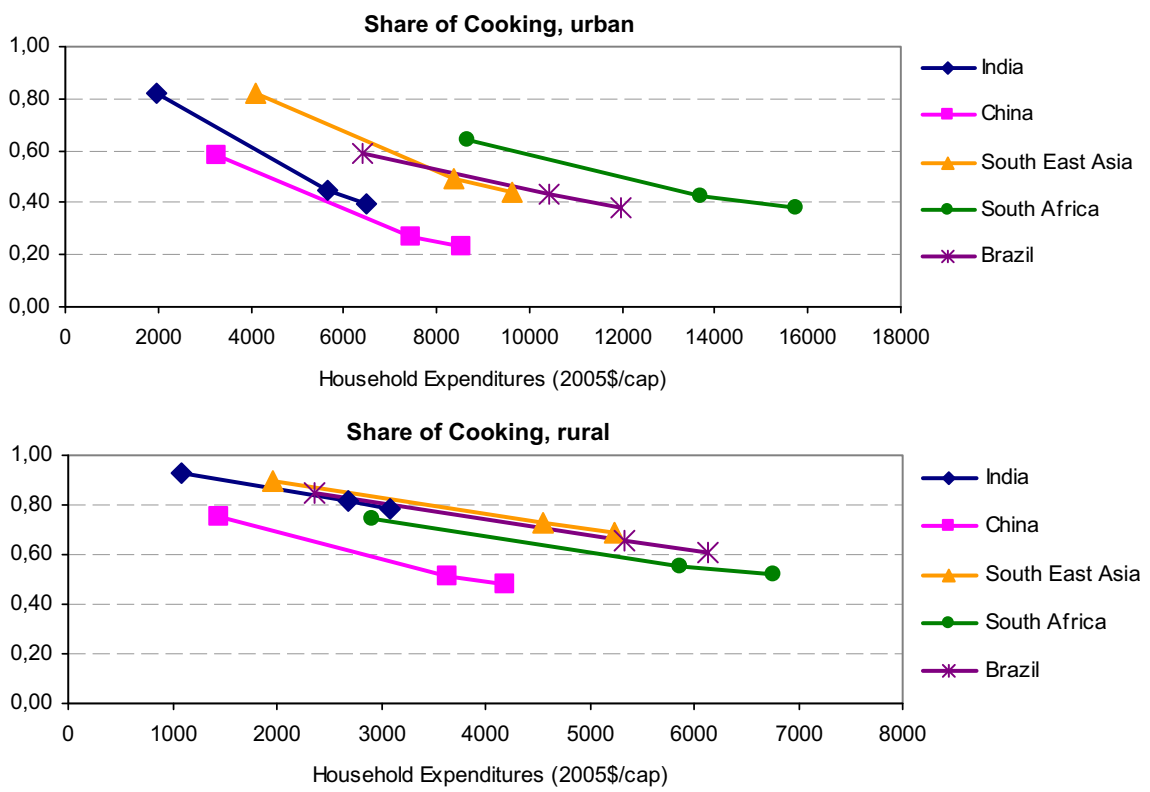

Fig. 9. Share of cooking in final energy use in 2007, 2030 baseline and $2030+15 \%$ on household expenditures, for urban (upper) and rural (lower) households.

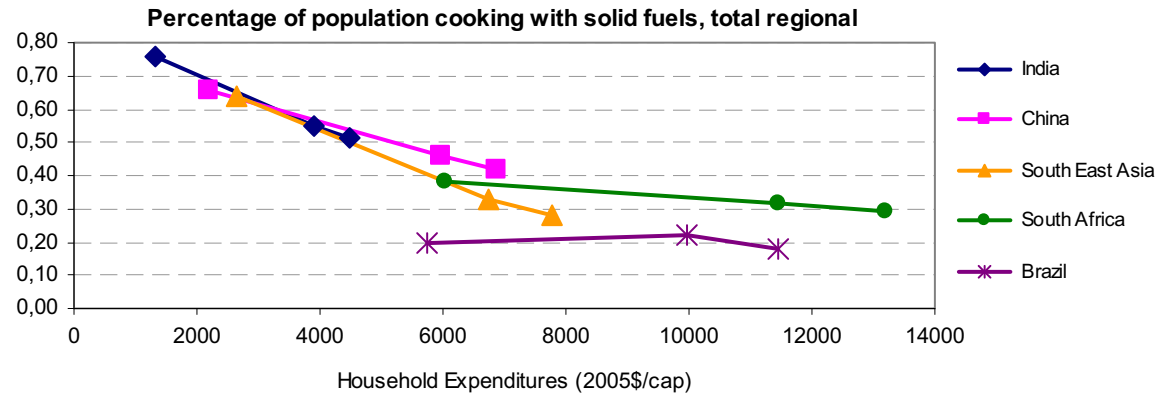

Fig. 10. Percentage of population dependent on solid fuels for cooking in 2007, 2030 baseline and 2030 with $+15 \%$ on household expenditures, total regional. 

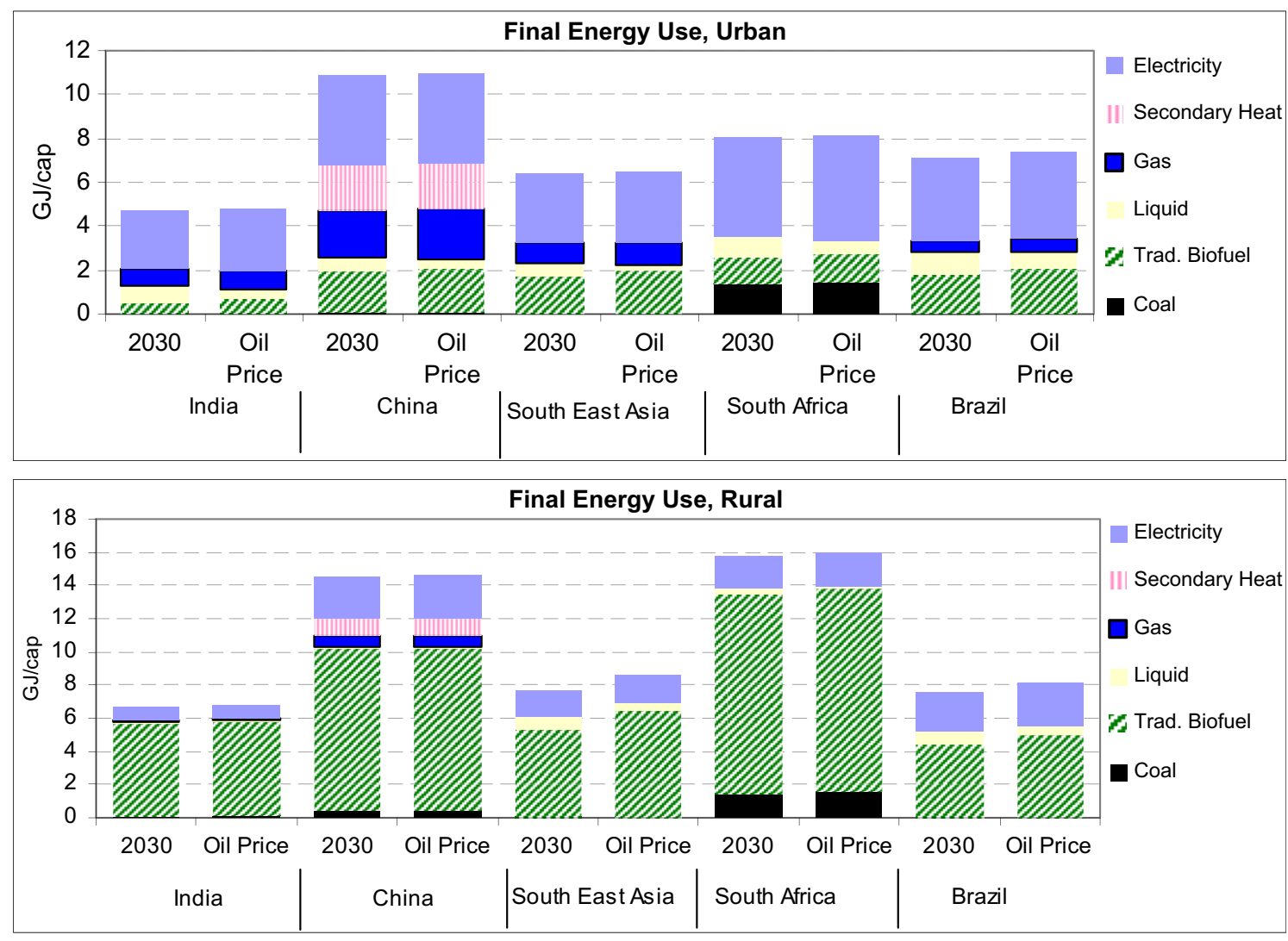

Fig. 11. Final energy use $\left(\mathrm{GJ}_{\mathrm{SE}} / \mathrm{cap}\right)$ under baseline and $15 \%$ increase in oil price in 2030 , for urban (upper) and rural (lower) households.

Fig. 9 shows the results of the sensitivity test on the share of final energy used for cooking. With a $15 \%$ increase in household expenditures this share decreases, but not significantly. For each region the lowest value of household expenditures is the 2007 value, the middle value is the 2030 baseline and the highest household expenditures show the $15 \%$ increase. For both urban and rural households the absolute decrease of the share of cooking is similar (3-6 percentage points).

Fig. 10 shows the effect of the increase in household expenditures on the percentage of population depending on solid fuels for their cooking needs. The total regional figures are indicated in order to avoid confusion due to urbanization rates. A $15 \%$ increase in household expenditures reduces the population cooking with solid fuel by $2-5$ percentage points.

Fig. 11 shows the effect on final fuel shares and final energy use of a $50 \%$ increase in the price of oil. The response to this change is rather limited. There is a small decrease in the use of liquid fuels (34-48\% for urban households and $25-48 \%$ for rural households) with minor increases in the other energy carriers, but mostly traditional biomass (and natural gas for urban households). Final energy demand in fact increases as the efficiency loss due to the increase in traditional biomass (with lower conversion efficiency) offsets the impact of energy savings.

\section{Climate policy}

Fig. 12 shows the carbon dioxide emission levels for urban and rural households for the baseline projections. These emissions have been broken down for emissions from commercial fuels, electricity and traditional fuels. It should be noted that although in Fig. 12 emissions from residential electricity are included; normally, however, these are attributed to the power sector. For traditional biofuels, the emissions are zero if harvested in a sustainable manner, but this is not necessarily always the case. It has been argued that $60 \%$ of fuel wood is harvested sustainably [66]. Here, we use this number (but the emissions without traditional fuel use emission can also be seen). Fig. 12 shows that with traditional fuel use emissions included, the total emission levels of urban and rural households are not very different; urban households have a higher share of commercial (including electricity) fuel emissions. The emissions from traditional fuels are projected to decrease for both urban and rural households due to fuel switching, but emissions from non-traditional fuels are projected to increase. This is in particular driven by the adoption of electricity for cooking or heating and increased use of appliances and cooling. Thus, while we earlier saw that fuel switching may lead to a decrease in final energy consumption; emissions are projected to increase in all regions for urban, and to a lesser extent rural, households. Emissions from commercial fuels are higher for urban households than rural households.

The importance of the power sector is evident in this analysis by comparing South Africa and Brazil. Both countries have similar welfare levels (in economic terms) yet different climatic conditions. As a result heating demand forms the main energy function for South African homes while the demand for space cooling grows significantly for Brazil. Despite this difference, both regions have similar final electricity use as in South Africa electricity is also for heating (Fig. 7). The resulting emissions are much larger in South Africa than Brazil as power is generated by coal power plants in the former and hydro power in the latter country (see Table 5).

In order to study how residential emissions may be reduced, an experiment was performed in which a carbon tax of $100 \$_{2005} / \mathrm{tCO}_{2}$ 

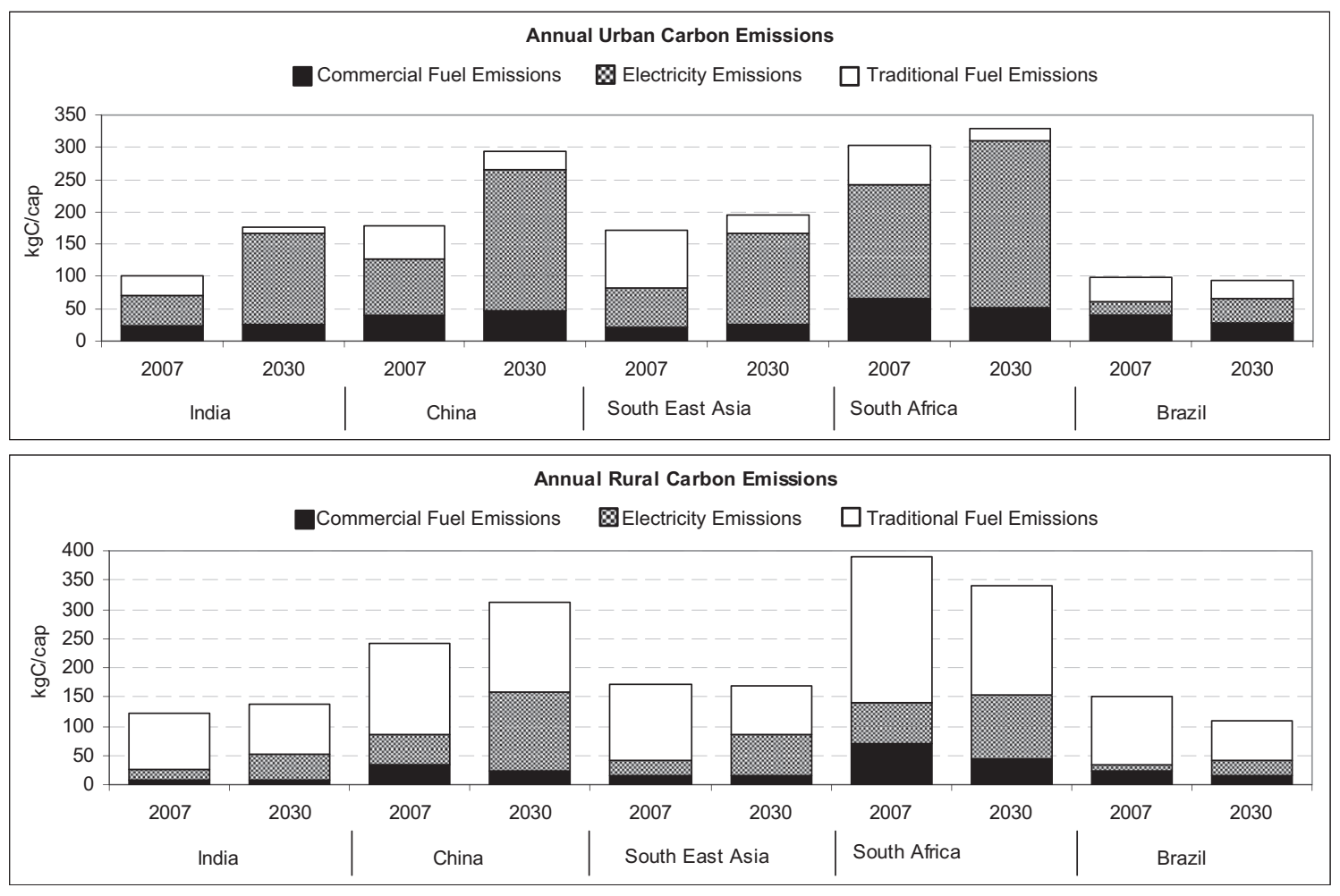

Fig. 12. Carbon emissions (including electricity) ( $\mathrm{kgC} / \mathrm{cap}$ ), with and without traditional fuels, for urban (upper) and rural (lower) households.

was introduced on commercial fuels but not on traditional fuels. Such a carbon tax does not only affect the fuel choices in the residential sector, but also influences the fuel choices in the power sector, changing its emission factor. In order to gain insight on this effect, the experiment was performed under the following conditions, 1) with the baseline emission factor for electricity, and 2) with an emission factor accounting for a response from the power sector to the carbon tax (see Table 5).

Fig. 13 shows the emissions in 2030 under the baseline and $100 \$_{2005} / \mathrm{tCO}_{2}$ tax projections under both electricity emission factor schemes. The constant emission factor column indicates the effect of the carbon tax only on the residential sector, while the variable emission factor column shows the effect on the combined residential and power sectors. Under the constant emission factor, in most cases the urban emissions from natural gas and liquid fuels increase, while electricity emissions decrease. Rural households move away from electricity towards liquid fuels due to lack of access to natural gas. A very important finding is that there is in fact a significant movement of rural households to traditional biomass which is not taxed (except for South East Asia and Brazil). If we account for changes in the power supply, the emissions from electricity decrease significantly due to de-carbonization of the electricity supply in all regions.

The taxing of commercial fuels gives rise to a somewhat unexpected side effect. The assumption that traditional fuels are not taxed implies that all other fuels get more expensive compared to traditional biomass. As a result, the transition from traditional fuels towards commercial fuels may be delayed and in some cases even reversed. This explains why in South Africa there is only a minor decrease in the use of coal and an apparent increase in the use of traditional biomass. Households in this region are currently depend strongly on electricity with a high emission factor which becomes more expensive under the tax scheme. Thus, households which depend on electricity show a small transition back to solid fuels. As shown in Fig. 14, the population strata who suffer most are those in the midst of fuel transition and thus most vulnerable to price hikes. For the rural households, the population dependent on solid fuels is in fact higher than in 2007. This also happens, to a lesser extent, to Indian and Chinese households. South East Asia and Brazil do not suffer from this side effect, which can be explained from respectively high baseline use of solid fuels and a clean electricity supply.

Concerning appliances, a higher price in electricity may lead to the purchase of more energy efficient units. Historically the energy intensity of large household appliances (refrigerators, washing machines, dish washers and clothes dryers) has decreased autonomously $[38,39,72-76]$. However data shows that the difference between the most and least efficient appliances constantly falls. As a result the cost for marginal improvements has been rising significantly (from an efficient appliance to an even more efficient one). This implies that the effect of price-driven climate policy on appliance UEC on an aggregate level is minimal.

\section{Discussion and conclusions}

From the above results, it is possible to come to certain conclusions concerning the questions we set out to answer in the beginning of the study.

$>$ This paper describes an innovative, global, bottom up model for residential energy use that allows us to better understand the underlying trends of energy use in developing countries. In this paper, we introduce the global residential energy model REMG. The model is able to reproduce many of the underlying dynamics that determine future residential energy demand. This model intends to provide additional insights into the transition in developing countries compared to more aggregated models. This includes issues like the provision of energy functions, fuel use/switching, inequality, urbanization, use of solid fuels for cooking and others. 

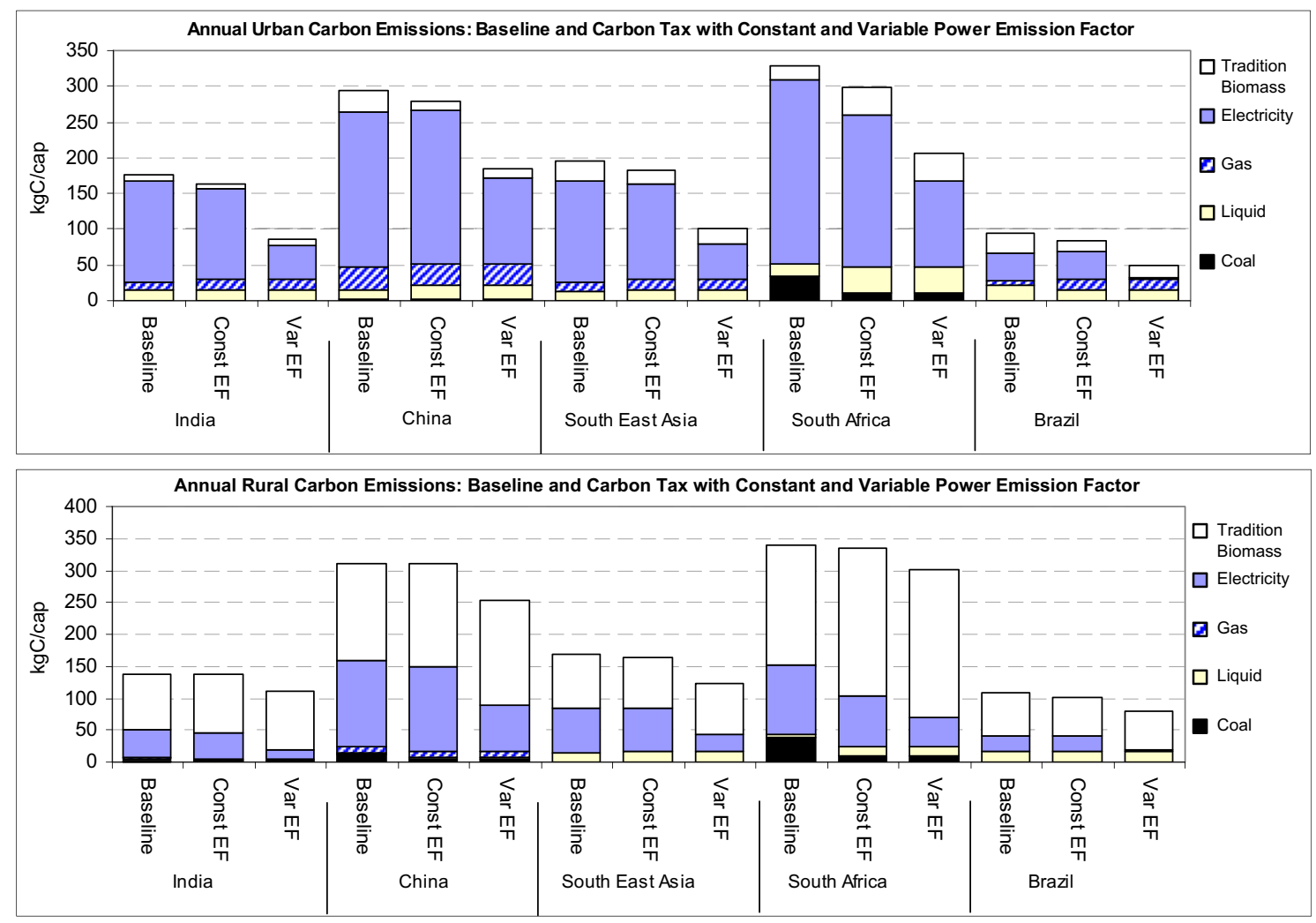

Fig. 13. Carbon emissions per capita under baseline and $100 \$ 2005 /$ tCO2 tax projections, for urban (upper) and rural (lower) households.

$>$ The model can still be further improved. The model can be improved with respect to data and the interpretation of some calibration factors. The model has been calibrated to available data, but no global data set with the required data exists. Using national scale data it was possible to calibrate the model in a way that was at the aggregate level consistent with the IEA data. With respect to the calibration factors, an important factor are the perceived prices. The drivers of fuel choice within the residential sector are only partly understood $[55,58,59]$. Factors such as cultural preferences have ended up as perceived costs in the REMG model and it might be useful to study these further.

$>$ Increases in the space heating/cooling, water heating and appliances and fuel switching from inefficient traditional fuels to more efficient modern fuels determine future energy demand. The projections show how useful energy demand increases with increased affluence. The model also shows that specific regional factors play a role in future energy use such as climatic conditions, accessibility to fuels and other regional preferences. The projections also show a fuel switch from traditional to modern fuels, resulting in a decrease in total energy use for some population groups. This is observed in urban South East Asia and South Africa and in all rural households except for China. The greatest growth is shown for China where the model predicts a $51 \%$ and $19 \%$ increase in final energy use for urban and rural households, respectively. A growth of $20 \%$ and $7 \%$ is expected for urban India and Brazil respectively. In rural households, cooking still remains the dominant end-use function by 2030. Yet there are significant increases in space heating demand, especially in China.

For urban households, electricity, liquid and gaseous fuels become the most used. In China, also secondary heat forms an important energy carrier. Coal is expected to be phased out, except in South Africa. In contrast, in rural households

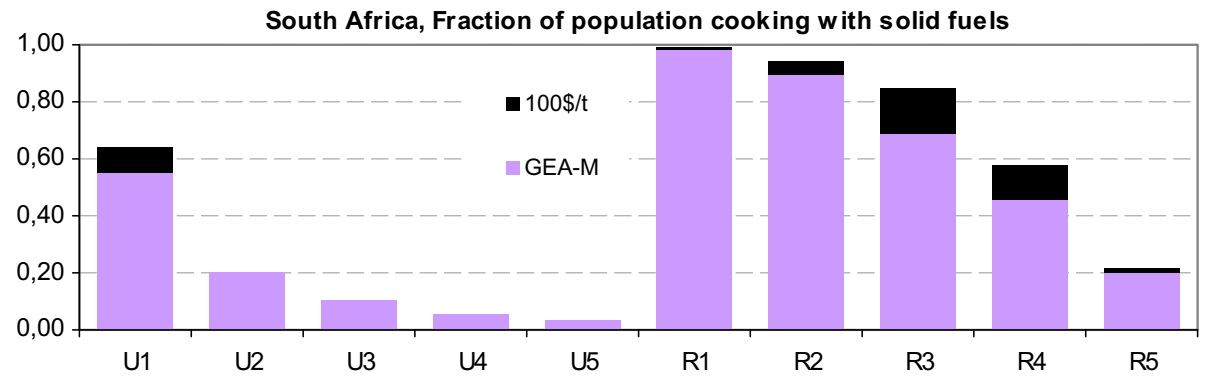

Fig. 14. Fraction of population cooking with solid fuels in South Africa in 2030 under baseline and $100 \$_{2005} /$ tCO2, urban/rural quintiles. 
traditional biomass still remains the dominant fuel by 2030 although electricity and liquid fuels gain market shares. In rural households, coal continues to be used by 2030 in China and South Africa.

$\triangleright$ Climate policy can reduce carbon emissions from residential energy use. However, climate policy may also slow down or even partly reverse the energy transition. Greenhouse gas emissions increase under the baseline projections in all regions. The calculations show that a carbon tax of $100 \$ 2005 / \mathrm{tCO}_{2}$ can significantly reduce emissions. Most of the reductions, however, come from a decarbonisation of the power sector. Similar conclusions have been made for the buildings sector of developed countries [71]. A possible negative side effect of the carbon tax is a switch from commercial to traditional fuels (which are not likely to be taxed) amongst households sensitive to price fluctuations. This side effect is in contrast to the co-benefits of climate policy which are often mentioned [77].

\section{Appendix. Supplementary data}

Supplementary data associated with this article can be found in the online version at doi:10.1016/j.energy.2011.10.044.

\section{References}

[1] IEA. 30 Years Of energy use in IEA countries. Paris: International Energy Agency; 2004.

[2] IEA. Energy balances. Paris: International Energy Agency; 2007.

[3] Pandey R. Energy policy modelling: agenda for developing countries. Energy Policy 2002;30:97-106.

[4] Shukla PR. Greenhouse gas models and abatement costs for developing nations. Energy Policy 1995;23(8):677-87.

[5] van Ruijven BJF, Urban RMJ, Benders HC, Moll JP, van der Sluijs D, van Vurren P, et al. Modelling energy and development: an Evaluation of models and concepts. World Development 2008a;36(12):2801-21.

[6] van Ruijven BJB, de Vries D, van Vurren P, van der Sluijs JP. A global model for residential energy use: Uncertainty in calibration to regional data. Energy 2009;35(1):269-82.

[7] Howell MI, Alfstad T, Victor DG, Goldstein G, Remme U. A model of household energy services in a low income rural African Village. Energy Policy 2005;33: 1833-51.

[8] Pachauri S. On measuring energy poverty in Indian households. World Development 2004;32(12):2083-104.

[9] Schipper L, Haas R, Scheinbaum C. Recent trends in residential energy use in OECD countries and Thier impact on carbon dioxide emissions: a Comparative analysis of the period 1973-1992. Mitigation and Adaptation Strategies for Global Change 1996;1:167-96.

[10] Ekholm T, Krey V, Shonali P, Riahi K. Determinants of household energy consumption in India. Energy Policy 2010;38:5696-707.

[11] McNeil MA, Letschert VE. Future air conditioning energy consumption in developing countries and what can be done about it: the potential of efficiency in the residential sector. In. ECEE 2007 Summer Study; 2007.

[12] McNeil MA, Letschert VE, de la Rue S. du Can. Global Potential of Energy Efficiency Standards and Labeling Programs. Berkeley: Lawrence Berkeley National Laboratory; 2008.

[13] Isaac M, van Vuuren DP. Modeling global residential sector energy demand for heating and air conditioning in the context of climate change. Energy Policy 2009;37:507-21.

[14] van Ruijven BJ, van Vuuren DP, De Vries B, Isaac M, van der Sluijs JP, Lucas P, et al. Model projections for household energy use in India. Energy Policy 2011;39:7747-61.

[15] IIASA. GEA scenarios: energy transition pathways for sustainable development. Laxenburg: International Institute of for Applied Systems Analysis; 2010.

[16] Daioglou V. Residential energy use scenarios. Utrecht: Utrecht University, GeoSciences; 2010.

[17] Hosier RH, Dowd J. Household fuel choice in Zimbabwe. Resources and Energy 1987;9:347-61.

[18] van Vuuren DP, den Elzen M, Lucas P, Eickhout B, Strengers B, van Ruijven B, et al. Stabilizing greenhouse gas concentrations at low levels: an assessment of reduction strategies and costs. Climatic Change 2007;81(2):119-59.

[19] NIS. Housing Conditions. Ministry of planning. Phnom Penh: National Insitute of Statistics; 2007. 2009.
[20] NSSO. Energy used by Indian households, Fifth quinquennial survey on Consumer Expenditure. New Delhi: National Sample Survey Organisation, Departement of statistics, Govt. of India; 1997.

[21] NSSO. Household consumer expenditure in India, NSS 60th Round. New Delhi: National Sample Survey Organisation; 2004.

[22] SSA. General Household survey. Pretoria; 2002.

[23] SSA. General household survey. Pretoria; 2007.

[24] WDI. World development indicators 2009 Database. The World Bank; 2009.

[25] NBSC. China statistical yearbook, various issues, Beijing: National Bureau of Statistics of China.

[26] World-Bank. Global income distribution dynamics Dataset. World Bank; 2009.

[27] World-Bank. PovcalNet: the on-line tool for poverty measurement developed by the Development Research Group of the World Bank. World Bank; 2010.

[28] Gangopadhay S, Ramaswami B, Wadhwa W. Reducing subsidies on household fuels in India: how will it affect the poor? Energy Policy 2005; 33(18):2326-36.

[29] Jannuzzi GM, Sanga GA. LPG subsidies in Brazil: an estimate. Energy for Sustainable Development 2004;8(3).

[30] LBNL. China energy Databook. Berkeley: Lawrence Berkeley National Laboratory; 2008.

[31] Peng W, Hisham Z, Pan J. Households level fuel switching in rural Hubei. Energy for Sustainable Development 2010;14:238-44.

[32] Tonooka Y, Liu J, Kondou Y, Ning Y, Fukasawa O. A survey on energy consumption in rural households in the fringes of Xian city. Energy and Buildings 2006;38:1335-42.

[33] Xiaohua W, Xiaqing D, Yuedong Z. Domestic energy consumption in rural China: a study on Sheyang country of Jiangsu Province. Biomass and BioEnergy 2002;22:251-6.

[34] WHO. WHO household energy Database. World Health Organisation; 2010.

[35] IEA. World energy Outlook. Chapter 15: Energy for Cooking in Developing Countries. Paris: International Energy Agency; 2006. 2006.

[36] Bogdan A, Bertoldi P. Residential electricity consumption in New Member States and Candidate countries. Energy and Buildings 2008;40:112-25.

[37] Cardoso RB, MNogueira LAh, Haddad J. Economic feasibility for acquisition of efficient refrigerators in Brazil. Applied Energy 2010;87:28-37.

[38] CEC. Historical appliances Database. The California Energy Commision; 2009.

[39] Weiss M, Junginger M, Patel MK. Learning energy efficiency - Experience Curves for household appliances and space heating, cooling and lighting technologies. Utrecht: Copernicus Institute; 2008.

[40] Amana. Refrigerator and washing machine ranges. accessed August 2010, www.amana.com; 2010.

[41] Dixons. Refrigerator and washing machine ranges. accessed August 2010, www.dixons.co.uk; 2010.

[42] Whirlpool. Refrigerator and washing machine ranges. accessed August 2010, www.whirlpool.com; 2010.

[43] Rong F, Clarke L, Smith S. Climate change and the long-term Evolution of the U.S.Buildings sector. Pacific Northwest National Laboratory; 2007.

[44] Sailor DJ, Pavlova AA. Air conditioning market saturation and long term response of residential cooling energy demand to climate change. Energy 2003;28:941-51.

[45] DoECC. Energy Consumption in the UK, Domestic data tables. Department of Energy and Climate Change; 2009.

[46] EIA. Residantial energy consumption survey, detailed tables: water/Space heating. Enenergy Information Administration; 2005.

[47] NRCan, Comprehensive energy use database, 1990 to 2007, natural resources Canada, Office for energy efficiency.

[48] Rosas-Flores JA, Galvez DM. What goes up: recent trends in Mexican residential energy use. Energy 2010;35(6):2596-602.

[49] Tyler S. What goes up: recent trends in Mexican residential energy use. Energy 1990;15(10):841-63.

[50] Utlu Z, Hepbasli A. Analysis of energy and exergy use of the Turkish residential-commercial sector. Building and Environment 2005;40:641-55.

[51] FSO. Economy and use of environmental Resources. Wiesbaden: Federal Statistical Office of Germany; 2010.

[52] IEA. Energy technology perspectives. scenarios and strategies to 2050. Paris: International Energy Agency.

[53] Mills E. The Specter of fuel-based lighting. Science 2005;308(5726):1263-4.

[54] Oosterhuis F. Cost decreases in environmental technology - Evidence from four case studies, R-07/05. Amsterdam: Institute for Environmental Studies Vrije Universiteit Amsterdam; 2007.

[55] Masera O, Saatkamp BD, Kammen DM. From linear fuel switching to multiple cooking Strategioes: a Critique and Alternative to the energy ladder model. World Development 2000;28(12):2083-103.

[56] Reddy S. Consumer discount rates and energy carrier choices in urban households. Internation Journal of Energy Research 1996;20:187-95.

[57] Train K. Discount rates in consumers' energy related Decisions: a review of the literature. Energy 1985;10(12):1243-53.

[58] Farsi M, Filippini M, Pachauri S. Fuel choice in urban Indian Households. Environment and Development Economics 2007;12(6):757-74.

[59] Maconachie R, Tanko A, Zakariya M. Descending the energy ladder? Oil price shocks and domestic fuel choices in Kano, Nigeria. Land Use Policy 2009;26: 1090-9.

[60] de Vries HJM, van Vuuren DP, den Elzen MGJ, Janssen MA. The image energy regional (TIMER) model. Bilthoven: National Institute for Public Health and the Environment; 2001. 
[61] van Vuuren DP, van Ruijven BJ, Hoogwijk MM, Isaac M, De Vries HJM. TIMER 2.0, Model description and appliactions. In: Bouwman AF, Hartman MPM, Klein Goldewijik CGM, editors. Integrated modelling of global environmental change. An overview of IMAGE 2.4. Bilthoven: Netherlands Environmental Assessment Agency (MNP); 2006.

[62] van Ruijven BJ, Schers J, van Vuuren DP. Model-based scenarios for rural electrification in developing countries. Energy, in press.

[63] Anozie AN, Bakare AR, Sonibare JA, Oyebisi TO. Evaluation of cooking energy cost, efficiency, impact on air pollution and policy in Nigeria. Energy 2007;32: 1283-90.

[64] Lefevre T, Todoc J, Timilsina GR, Trossero MA. The role of wood energy in Asia. FAO; 1997.

[65] Lucky RA, Hossain I. Efficiency study of Bangladeshi cookstoves with an emphasis on gas cookstoves. Energy 2001;26:221-37.

[66] Reddy S, Balachandra P. Climate change mitigation and business opportunities - the case of the households sector in India. Energy for Sustainable Development 2006;10(4):59-73.

[67] Saidur R, Masjuki HH, Jamaluddin MY, Ahmed S. Energy and associated greenhouse gas emissions from household appliances in Malaysia. Energy Policy 2007;35:1648-57.

[68] Visser P. The testing of cookstoves: data of water boiling tests as a basis to calculate fuel consumption. Energy for Sustainable Development 2005;IX(1): 16-24.
[69] IIASA. GEA scenario Database. International Institute of Applied Systems Analysis; 2009.

[70] IEA. Energy technology Perspectives: scenarios and strategies to 2050. Paris: International energy Agency; 2010b.

[71] Kyle P, Clarke L, Rong F, Smith S. Climate policy and the long-term Evolution of the U.S. Building sector. The Energy Journal 2010;31(2):145-71.

[72] Consumentenbond. Consumentengids. Mandblad van de Nederlandse Consumentenbond. The Hague: Consumentenbond; 1964-2008.

[73] Dale L, Antinori C, McNeil MA, McMahon J. Retrospective evaluation of declining price for energy efficient appliances. Lawrence Berkeley National Laboratory; 2002.

[74] EES. Greening whitegoods: a report into the energy efficiency trends of major household appliances in Australia from 1993 to 2005. Energy Efficient Strategies; 2006.

[75] Laitner JA, Sanstad AH. Learning-by-doing on both the demand and the supply sides: Implication for electric utlity investments in a heuristic model. Internation Journal of Energy Technology and Policy 2004;2: 142-52.

[76] Schiellerup P. An Examination of the EU minimum energy standard on cold appliances: the British case; 2001.

[77] Nemet GF, Holloway T, Meier P. Implications of incorporating aitr-quality cobenefits into climate change policymaking. Environmental Research Letters 2010;5(1):10. 